\title{
Important differences: Canadian Diabetes Association 2008 clinical practice guidelines and the consensus statement of the American Diabetes Association and the European Association for the Study of Diabetes
}

\author{
V. Woo
}

Received: 18 November 2008 / Accepted: 18 November 2008 / Published online: 24 December 2008

(C) Springer-Verlag 2008

\section{Abbreviation \\ CDA Canadian Diabetes Association}

The evidence-based Canadian Diabetes Association (CDA) 2008 clinical practice guidelines for the prevention and treatment of diabetes [1] differ from the guidelines in the consensus statement by Nathan et al. [2], although both were published at almost the same time.

The consensus statement, which represents the authors' collective analysis, evaluation and opinion, is said not to represent official association opinion, yet is listed as a consensus statement of the American Diabetes Association (ADA) and the European Association for the Study of Diabetes (EASD). In contrast, the CDA clinical practice guidelines do represent the official position of the CDA. The CDA guidelines follow the Appraisal of Guidelines for Research and Evaluation (AGREE) instrument [3] and have a standardised evidence-based approach to all recommendations. There are more than 90 authors and a steering

V. Woo on behalf of the Steering Committee of the Canadian Diabetes Association 2008 clinical practice guidelines for the prevention and treatment of diabetes.

V. Woo $(\bowtie)$

Health Sciences Centre, University of Manitoba,

Winnipeg, MB, Canada R3E 3P4

e-mail:woovc@cc.umanitoba.ca committee of 18 , and all recommendations have $100 \%$ approval from the steering committee and the authors of each chapter. This removes as much bias as possible. The ADA/EASD consensus group consists of seven members and emphasises 'our collective knowledge and clinical experience, which takes into account benefits, risks and costs...'. Neither publication specifically provides a cost analysis. The CDA believes cost analyses are inconsistent in methodology and lack assessments on hypoglycaemia and quality of life, and therefore omitted them.

The algorithms differ in the choice of medications to prescribe when metformin fails to control hyperglycaemia. In contrast to the consensus statement, which has a two-tier system, the CDA guidelines give equal weight to the following classes of medications that are available in Canada (listed alphabetically): alpha-glucosidase inhibitors, dipeptidyl peptidase 4 (DPP-4) inhibitors, insulin, insulin secretagogues, thiazoledinediones and weight-loss agents.

It is of concern that the consensus paper has a two-tier approach with only basal insulin and sulfonylureas as the preferred choices after metformin. Our committee believes that patients and practitioners deserve more choice. Nathan et al. state that they take costs into account, but they do not factor self-monitoring of blood glucose into their algorithm. In addition, the consensus statement does not recommend glibenclamide (known as glyburide in the USA and Canada), which is probably the least expensive sulfonylurea, and it further states that sulfonylureas should be discontinued when insulin is used. Therefore, when basal 
insulin with an intermediate-acting insulin is used it is very likely that more than one injection will be required.

With regard to thiazoledinediones, we have not found that there is evidence to exclude rosiglitazone, based on recent evidence from the Action to Control Cardiovascular Risk in Diabetes (ACCORD), Rosiglitazone Evaluated for Cardiac Outcomes and Regulation of Glycemia in Diabetes (RECORD) and VA Diabetes (VADT) trials [4-6], which do not show an increased risk of myocardial infarction. Moreover, these trials were specifically designed to address this question, in contrast to the studies quoted in the consensus statement.

In summary, both approaches have merits but differ in important ways. The CDA evidence-based approach gives more flexibility, while the consensus approach is more directive and more opinion-based.

Duality of interest V. Woo has received fees for advisory boards and/or speaker fees from: Bristol Myers Squibb, Astra Zeneca, Merck Frosst, Glaxo Smith Kline, Novo Nordisk, Eli Lilly, Norvartis and sanofi-aventis. The Steering Committee has duality of interests listed at http://www.diabetes.ca/files/cpg2008/dualities-of-interest.pdf.

\section{References}

1. Canadian Diabetes Association Clinical Practice Guidelines Expert Committee (2008) Canadian Diabetes Association 2008 clinical practice guidelines for the prevention and management of diabetes in Canada. Can J Diabetes 32(Suppl 1):S1-S201 Available from http:/www.diabetes.ca/files/cpg2008/cpg-2008.pdf, accessed 21 November 2008

2. Nathan D, Buse J, Davidson MB et al (2008) Medical management of hyperglycaemia in type 2 diabetes: a consensus algorithm for the initiation and adjustment of therapy. A consensus statement from the American Diabetes Association and the European Association for the Study of Diabetes. Diabetologia doi:10.1007/ s00125-008-1157-y

3. The AGREE Collaboration (2003) Development and validation of an international appraisal instrument for assessing the quality of clinical practice guidelines: the AGREE project. Qual Saf Health Care 12:18-23

4. The Action to Control Cardiovascular Risk in Diabetes Study Group (2008) Effects of intensive glucose lowering in type 2 diabetes. N Eng J Med 358:2545-2559

5. Home PD, Pocock SJ, Beck-Nielsen J (2008) Rosiglitazone evaluated for cardiovascular outcomes - an interim analysis. $\mathrm{N}$ Eng J Med 357:28-38

6. American Diabetes Association (2008) Intense blood glucose control yields no significant effect on CVD reduction in VA Diabetes Trial. Available from http://www.diabetes.org/for-media/ pr-intense-blood-glucose-control-yields-no-significant-effect-oncvd-reduction.jsp, accessed 21 November 2008 